\title{
Subcutaneous Placement of Access Ports following Laparoscopic Adjustable Gastric Banding is a Safe, Cost-Effective Technique Associated with Low Complication Rates
}

\author{
Richard J. Egan • James E. Coulston - Sally A. Norton • \\ Justin D. Morgan
}

Published online: 5 August 2010

(C) Springer Science+Business Media, LLC 2010

\section{Dear Authors,}

We read with interest your article regarding the incidence of access port complications in your unit [1]. Our centre has a particular interest in this controversial topic, and our results have been published previously [2].

The number of patients suffering with access port complications in your cohort, namely $14.5 \%$, is consistent with many published series [3, 4]. One thing that links the vast majority of such reports is the mechanism used to secure the access port $[3,4]$. Most authors prefer to fix the port to the rectus sheath using non-absorbable sutures, with the rationale that this reduces the risk of port migration or rotation, and subsequent need to re-site the port $[5,6]$. Recent advances in access port application have included the development of port fixation devices, which are growing in popularity [6].

Our preferred technique is to place the port subcutaneously, without fixation, in a snug pocket. This is simply established with gentle digital dissection prior to closure of the overlying tissues. As previously published by our group, access difficulties occurred in only $2 \%$ of our patients [2]. Approximately half of these patients ultimately required port repositioning under local anaesthesia at a later date. To date, we

The authors declare that they have no conflicts of interest

R. J. Egan $(\bowtie) \cdot$ J. E. Coulston

Surgical Registrar, Department of General and Bariatric Surgery,

Southmead Hospital,

Westbury-on-Trym,

Bristol, UK BS10 5NB

e-mail: richard.egan@nbt.nhs.uk

\section{S. A. Norton · J. D. Morgan}

Consultant Surgeon, Department of General and Bariatric Surgery,

Southmead Hospital,

Westbury-on-Trym,

Bristol, UK BS10 5NB have operated on 340 patients at a single site. Our total access port complication rate still remains under $3 \%$. We have had only one re-operation due to puncture of the tubing, and to date have had no abscesses or deep infections associated with the access port.

It is our recommendation that surgeons performing laparoscopic adjustable gastric banding as a routine consider this simple and ultimately time-saving technical modification, to ensure low access port complication rates. We have not noted an increased risk of port rotation, migration or erosion as a result of our technique, and our methods are almost universally accepted by our patient group. Accessing the port is simplified by its subcutaneous positioning, and our negligible rate of tube fracture or disconnection is thought to be the result of removing the direct shearing forces which can occur following forceful contraction of the rectus apparatus.

\section{References}

1. Lattuada E, Zappa MA, et al. Injection port and connecting tube complications after laparoscopic adjustable gastric banding. Obes Surg. 2010;20(4):410-4.

2. Arvind N, Bates SE, Morgan JD, et al. Fixation of the access-port is not required in gastric banding. Obes Surg. 2007;17(5):577-80.

3. Susmallian S, Ezri T, Elis M, et al. Access-port complications after laparoscopic gastric banding. Obes Surg. 2003;13:128-31.

4. Korenkov M, Sauerland S, et al. Port function after laparoscopic adjustable gastric banding for morbid obesity. Surg Endosc. 2003;17:1068-71.

5. Eid GM, Gourash W, Collins JL. A novel technique for fascial fixation of laparoscopic adjustable gastric band ports. Surg Endosc. 2006;20:697-9.

6. Miller KA, Pump A. Mechanical versus suture fixation of the port in adjustable gastric banding procedures; a prospective randomized blinded study. Surg Endosc. 2008;22(11):2478-84. 